\title{
Active Seniors Perceived Value within Digital Museum Transformation
}

\begin{abstract}
Purpose - This paper will answer fundamental questions on the perceived value of active senior visitors $(55+$ years old) in the context of cultural heritage sites, when using immersive technologies, conceptualizing technological experience by illustrating an extended space in the pre, during, and post phases of visits. Furthermore, it will reveal a better understanding of digital transformation opportunities and risks in the tourism industry and its related sectors regarding active senior travelers and it will further provide some insights and tools that are required to follow. Design/methodology/approach - Since we are studying a population that is thus far not fluent in the means of digital opportunities, we will conduct two semi-structured interviews before and after visits to the museums in order to lower the level of emotional bias responses. Moreover, observations of the participants' interaction with technological devices will be assessed during their visit.

Findings - Current findings enrich the theoretical perspective of perceived value. First, they extend our knowledge on the perceived consumers' value of active senior visitors in the application of immersive technologies pertaining to archeological museums. They also shed new light on the different dimensions of the perceived value (epistemic value; functional value; hedonic value and social value) of active senior visitors concerning museum transformation. Third, they provide an integrative framework for extending the bounderies of the museum technological visit experience: linking the pre, during and post visit phases.

Research limitations/implications - Having a longitudinal study that evaluates the same population of seniors over a longer period would enhance our understanding of perception and adoption behavior in non-users. It entails the dimensions that are necessary from a theoretical and managerial point of view, thus contributing to strategic planning for museum managers who are planning on going digital in the coming years aiming at creating further value and satisfaction for their active senior visitors to cultural heritage sites.

Originality/value - The majority of research concerning technological developments and experiences to date has focused on holistic views studying different stakeholders' perspectives or on digital natives' perception regarding museum digital transformation. However, only few studies have evaluated the perceived value of active senior travelers and their overall satisfaction when visiting museums that became digital.
\end{abstract}

Keywords Active senior visitors, Immersive Technologies, Level of engagement, Perceived experience value, Cultural heritage, digital transformation.

Paper type Case study 


\section{Introduction}

Innovative technologies such as smartphone applications and wearables are playing a central role in the way people nowadays access, share and transfer information. In fact, the typical Internet user swims in a sea of social media (Kaplan \& Haenlein, 2010). Museums are offering their services while tending to evolve in line with the developments that are occurring in the society (ICOM, 2007). Consequently, this trend is widening the use of mainstream technologies; also social media has created the need for museums to adapt to lifestyle changes thus endeavoring to further engage their visitors during their visit. Accordingly, museums have started to allocate additional resources in order to digitize their collections and to publicize themselves over the web (Hogsden \& Poulter, 2012). In other terms, museums are looking into new developments in media and technology as a means for innovative interaction with art, thus providing a greater engagement with the exhibits and ensuring better customer service (Buhalis, 2003; Stogner, 2013). Moreover, the value deriving from social commerce networks (social media and commercial activities) is creating a direct tie between the visitors and the museum thus generating "consumer-generated media" such as reviews and recommendations that provide some good economic value in the context of marketing and retailing when customers are better engaged and satisfied (Stephen and Toubia, 2009, Liang and Turban, 2011).

However, despite the popularity of these types of new technological means and social media among digital natives, senior citizens are still unable to fully enjoy what is offered. Much of the literature focuses on the digital divide that elderly seniors face with internet usage together with their cognitive and physical difficulties (Welsh, Alijani, \& Smith, 2009).

The majority of research concerning technological developments and experiences to date has focused on holistic views studying different stakeholders' perspectives (Dieck \& Jung, 2017) or on digital natives' perception regarding museum digital transformation (Muskat M., Muskat, B., Zehrer, \& Johns, 2013), in order to ensure that museums will be relevant and valuable to future generations (OP\&A, 2007). However, only few studies have evaluated the perceived value of active senior travelers and their overall satisfaction when visiting museums that became digital, knowing that active seniors represent the biggest market for archeological and art museums.

Therefore, the present study will examine the perceived experience value of active senior travelers $(55+$ years old $)$ in the context of cultural heritage sites and specifically at museums.

In order to address this fundamental breakthrough in the promotion and preservation of cultural legacy, it is important to understand active seniors' travelers' perception over the whole experience of museum digital transformation to provide better services and equitable participation for all without marginalizing any group. Hence, the present work answers first fundamental questions on perceived experience value of "Active senior visitors" with regards to the fast technological change through illustrating an extended space in the pre/during/post phases of visit. Second, it provides detailed insights into the perceived value of immersive technologies and social media on a less studied population that is forecasted to represent a third of the European Unions (EU) population in the next twenty years (Eurostat, 2016) and is considered an affluent fast growing market and a driving force in the tourism industry (Schröder, Achim, \&TorstenWidmann, 2007). Further, seniors who have high levels of purchasing power are becoming more active in the society and traveling much more (Huang \& Tsai, 2003). Third, it entails the dimensions that are necessary from a managerial point of view, thus contributing to strategic planning for museum 
managers who are thinking of going digital in the upcoming years and creating further value and satisfaction for their active senior visitors at cultural heritage sites.

\section{Museum Transformation within societal Lifestyle Changes}

In the last three decades, a wide range of private and public organizations in different fields have recognized the beneficial potentials of the new digital technologies, and have implemented strategies to address digital transformation in their respective managements and operations (Matt, Hess, \& Benlian, 2015). Also, the tourism field has always been in the forefront for embracing technological innovations (Gretzel, 2011) since information and communication technologies (ICT) are continuing to serve as the main driver for tourism innovations (Atembe, 2015).

Today, visitors expect to use integrative products that can help them find relevant information before and during their trip as well as manage to share and capture their experience during and after their visit (Johnson, Adams Becker, Estrada, \& Freeman, 2015). In order to develop such an adequate integrated system, a deep understanding of tourist needs with respect to technology development is required to generate valuable and enjoyable destination experience (McCabe, 2014). Also, museums are trying to better understand their diverse audiences in order to meet future visitors' needs (Hooper-Greenhill, 2006). In fact, they have gradually acquired visitor-based roles instead of museum based role (Weil, 2007) hence further engaging their visitors and cocreating glamorous experiences for them (Sfandla \& Björk, 2013).

Much of museums' energy is spent on attracting people into their premises, this implying the need for making bold changes in marketing, programming and infrastructure in order to fill in the participation gap that they are struggling to achieve (OP\&A, 2007). The introduction of innovative and new means of technological devices was a step forward to become more appealing to the "internet generation" who having the constant need to be "continuously connected" will be thus enabled to use their smartphones and other preferred means of devices. Moreover, the rapid development of smartphone devices has made gaming popular and attractive to a broader group of players and started to be used in tourism (Xu, Weber, \& Buhalis, 2013). Hand-held gaming, such as touch screen audio-video guides and mobile augmented reality (AR) applications, were introduced as innovative products of engagement.

Hence, museum mobile applications give the consumer the ability to explore the exhibits before, during and after the visit (Economou \& Meintani, 2011). Furthermore, they develop the consumer/museum relationship by allowing visitors to read, collect data and share their experiences on social media during or even after their visit. This provides a mechanism for expanding the museum out into the world, but also inviting the world to dwell into the museum (Ippolito\& Bell,2015).

Meanwhile, changes bring challenges, since each organization is different than the other and needs tailored strategies to succeed (Johnson et al., 2015). In this regard, Morison, Alex (2017) emphasized the nature of museums by stating eight factors that explain why museums need distinct digital strategies compared to those of the business world. Yet, it is unclear how museums are dealing with their seniors' heterogeneity and their use of these new technologies.

\section{Active Senior Travelers' Heterogeneity and Use of Technology}

The overall population of seniors is growing worldwide. In fact, according to the World Health Organization (WHO, 2015), the number of people aged 60 years and older will outnumber children 
younger than 5 years by 2020, and by 2050 they will represent nearly $22 \%$ of the world's population, totaling approximately 2 billion.

Effectively, the senior market is considered one of the fastest growing segments and a driving force in the tourism industry (Schröder, Achim, \& Torsten Widmann, 2007). Nowadays, seniors are traveling more frequently and are becoming more active in the society (Huang \& Tsai, 2003). With the aging population in developed countries, tourism researchers are becoming more attentive to the quality of life and the experiences of senior travelers regarding a variety of related issues such as their behavioral patterns (Jang, Bai, Hu, \&Wu, 2009), travel expenditure (Jang \& Ham, 2009), travel constraints (Kazeminia, Del Chiappa, \& Jafari, 2015), travel motivation (Patuelli \& Nijkamp, 2016; Jang et al., 2009; Jang \& Wu, 2006) and satisfaction.

Recently, seniors are showing more interest and motivation in learning and interacting with ICT products (Eriksson \& Fabricius, 2015). This led researchers to focusing their studies firstly on both seniors and information communication technologies, but also on the Internet, and more recently on mobile applications and the use of Augmented Reality (AR) (Im et al., 2015; Saracchini et al., 2015). Some of these studies have focused on searching for new ways to help and improve the self-esteem of those seniors who are unfamiliar with the world of digital technologies, as a means to increase their independence, personal happiness and social inclusion, as well as the accessibility and affordability of related technologies.

In addition, some of the literature is focusing on the digital divide that elderly seniors are facing when dealing with internet usage together with their cognitive and physical difficulties (Welsh et al., 2009). Nevertheless, this divide is gradually diminishing (McMurtrey et al., 2011), as more seniors are using the internet and technological devices (smart phones and tablets) in their daily lives (Kim et al, 2016; Pesonen et al., 2015). However, their use tends to engage them in fewer activities which is limiting the comprehensive exploitation of the immense potential that the web can offer (Haight et al., 2014). Based on that, several studies in different fields have revealed the positive effects of internet use and the ICTs on the wellbeing and quality of life of seniors (Caro et al, 2016; Gustafson et al, 2015).

Anabel Quan-Haase, Kim Martin \& Kathleen Schreurs (2016) focused their study on the activities that motivate digital seniors to engage in the use of the ICT in their daily life. The study revealed that when seniors, like any other segment of the population, are presented with technologies that are beneficial for their way of life, they tend to adopt them more readily (Kok, Williams, \& Yan, 2012), especially if such technologies will increase the level of their mental well-being (Cotten \& McCullough, 2013).

Senior travelers represent quite a heterogeneous market with respect to the use of tourism information technology. Pesonen et al. (2015) presented a tentative typology of three different types of senior travelers based on their use of online travel services: 1) Adventurous experimenters (seniors who are avid users of the internet; they prefer to be independent during their travel and select new destinations; have higher education achievements, better language skills and more adventurous mindsets); 2) Meticulous researchers (they are mainly seniors who just log into the internet in search for information; they tend to prefer booking package holiday tours, want to learn new things, and value safety and certainty); 3) Fumbling observers (Seniors who do not use the internet since they have not had previous experience with computers; they value safety, so they focus on package holidays, and engage only in the mother tongue language. These travelers tend to have a low education level). 
Many research works have conducted experimental studies with senior citizens who had to learn how to use new devices and applications. These studies proved that once seniors acquired more knowledge regarding the usability of the technological devices in their daily life, they became more motivated to deepen their learning and usage of the ICT products (Caro et al, 2016).

\section{Customer Perceived Experience Value in The Service Industry}

To satisfy their customers, managers of tourism services need to understand their value requirements and then develop unique service value offerings based on those requirements (Gregory, Dess, Lumpkin, \& Einer, 2010). It is increasingly recognized that customer perceived experience value in the service industry matters greatly to managerial strategic planning and is considered one of the key determinants of an organizational success or failure (Stickdorn \& Schwarzenberger, 2016). In fact, when organizations satisfy people-based needs, they are delivering value, which puts them in a much stronger competitive advantage position in the long term (Grant, 1991).

Perceived value has long attracted much attention from both industry and academia (Siu, Zhang, Dong, \& Kwan, 2013). It is a subjective, complex and multi-dimensional construct (SánchezFernández \& Iniesta-Bonillo, 2007) that varies among customers (Parasuraman, 1997), among cultures and at different times (Holbrook, 2006). This appreciation considers perceived value as a dynamic variable that is experienced before purchase, at the moment of purchase, at the time of use, and after use (Sheng \& Chen, 2012; Falk \& Dierking, 2000).

Given this central role, the phenomenon of perceived value has been addressed with a set of rich theoretical perspectives (Zeithaml, 1988; Sheth, Newman, \& Gross, 1991; Sweeney \& Soutar, 2001; Wang, Lo, Chi, \& Yang, 2004; Holbrook, 2006).

In museum experience, Falk and Dierking (2000) referred to museum experience as a gestalt (learning experience) that can vary from one person to another when three contexts interact or overlap at three different phases of the visit: 1) the "Personal context" which occurs prior to the visit. It mainly refers to visitors' education, expectations, prior knowledge, experience, prior interest, belief, choices they had, and control over such choices; 2) the "Physical context" that occurs during the visit and it refers to the museum's display of objects and the services provided to visitors; 3) and finally the "Social context" which occurs after the visit and it reflects visitors" identity status within their social entourage and lately through their use of social media.

\section{Pre-visit}

In order to probe visitor experience, it is necessary to understand visitors'expectations before the visit (Sheng \& Chen, 2012). Falk and Dierking (2000) argue that museum managements should think about users in terms of their needs. Accordingly, they identified five "experience types" that describe basic human needs: 1) Explorers: they are motivated by personal curiosity; 2) Facilitators: they are motivated by other people and their needs; 3 ) Experience-Seekers: they are motivated by the desire to see and experience a place (i.e. tourists); 4) Professional/Hobbyists: they are motivated by specific knowledge-related goals (i.e. scholars researching a specific topic); 5) and finally Rechargers: they are motivated by a desire for a contemplative or restorative experience.

Larsen (2007) asserts that planning in advance would influence the actual experience as tourists would expect possible events that would influence their emotional and cognitive aspects before and even after the visit. 
In industries where new technologies have to be utilized, Chung, Han, and Joun (2015) found three factors that encourage the use of AR mobile applications. The first aspect is technology readiness, the second is the visual usage and the third is the situational factor.

\section{During-visit}

Tourists play an active role in co-creating value-in-use through the contribution of resources that they encounter during their visit (Presbensen, Vitterso \& Dahl, 2013). Moreover, introducing new products in any business is pivotal as they affect long term business plans, and have a positive impact on both financial (enhance sales) and non-financial (creating competitive advantage, loyalty and meaningful experiences for customers) aspects (Siu et al, 2013).

In this regard, Kourouthanassis, Boletsis, Bardaki, and Chasanidou (2015) comprehensively demonstrated that the functional properties of Mobile Augmented Reality (MAR) application will evoke feelings of arousal which in turn will influence the behavioral intention of adopting it. In addition, De Rojas and Camero (2008) examined the dynamic interaction between quality and emotion as a determinant of satisfaction.

\section{Post-visit}

Chung et al (2017) revealed that content, personalized service, and system quality will affect users' satisfaction and intention to recommend AR applications. This is in conformity with the study of Wang and Chen (2011) that stresses on the quality dimension of technological devices which is essential for acquiring customers' satisfaction and thus their loyalty. Visitors tend to express their feeling of satisfaction through social media. On their side, Cabiddu, De Carlo, and Piccoli (2014) identified three distinctive social media affordances for customer engagement in tourism: Persistent engagement, customized engagement, and triggered engagement.

Finally, museum operation managers must consider in their digital strategies, how to carefully order and structure their exhibit digital data, especially outside the walls of the museums, in order for its content to reach a greater audience and be useful for everyone who would like to view, share, re-purpose and re-contextualize museum data (Kraemer \& Kanter, 2014).

\section{Methodology}

\section{Research Design and Settings}

This work is based on a qualitative study. Qualitative research allows for more detailed accounts of the processes and nuances under investigation. An inductive, single case research design was used. It is argued that the adoption of formal inductive procedures can represent an important step towards assuring conviction in qualitative research findings (Baxter \& Jack, 2008). According to Yin (1994), the single case study is the preferred research approach when "How" or "Why" questions are being asked. Moreover, the single case study is considered a suitable research design when it is intended to investigate in-depth a multifaceted social phenomenon (Merriam, 1998).

The main focus of our study is to understand how the introduction of new means of technological devices and immersive technologies at archeological museums is perceived by senior visitors as well as if this is affecting their overall satisfaction. 
First, among other constellations of cultural heritage sites, specifically the museums were chosen, because they summarize the historical and archeological heritage in a relatively small location. Moreover, since we are considering studying senior travelers who represent a population that may have physical constraints, it was preferred to select a cultural heritage site where seniors can relatively feel safe, have easier access to its facilities (toilets, elevators and air-conditioning) and are able to explore and get in touch with their cultural relevance.

Second, we selected the case study according to the following criteria: 1) transparency: since we had full access to key information (Pettigrew, 1990; Tsoukas, 2010) and a good background knowledge of the museum and its environment, such as its history, visitors segments, competitors, work habits and routines (Sandberg \& Tsoukas, 2011); 2) the occurrence of investments in immersive technologies in the establishment aiming at addressing and implementing the digital transformation; 3) and the exploitation of a unique archeological attraction.

In application of the aforementioned criteria, we selected the National Archaeological Museum of Cagliari as the site of our present research. In 2013, the National Archaeological Museum of Cagliari implemented the first part of their digitization investment plan by developing its virtual building tour and making it available on its blog. In the same year, the museum created its social media channels, taking another step towards the process of digitization and paving the way for its first attempt at a new avenue in communicating with its visitors. In 2016, the museum became "liquid". In fact, it was renovated with the latest technologies with a special attention given to its content that was exhibited to be accessible for all. Finally, it became the only museum in the world which has managed to show the Nuragic Civilization Era through media and technological tools. Consequently, the National Archaeological Museum of Cagliari figures as a suitable entity for our study since it enables us to observe the phenomenon of digital transformation at the very moment of its occurrence.

\section{Data Collection}

In the tourism industry, most customer feedback and search for relevant information are taking place online. However, since we are studying a population that is so far not fluent in the means of digital opportunities, we conducted two quick semi-structured interviews before and after the visit to the museum to lower the level of emotional bias responses. Also, observations of the participants' interaction with technological devices were assessed.

The interview questions were all open-ended (see Annex 1). Three main phases of the tourism process were taken into consideration to evaluate the overall experience and the level of engagement of active senior travelers with their environment when using new technologies implemented in the archeological museum. Our design embedded four perception value dimensions through an extended space in the pre/during/post phases of visit: 1- during the previsit, we studied the epistemic value dimension; 2-during the visit we handled the hedonic and functional dimensions; and 3-during the post-visit we concentrated on the social value dimension. In the first interview, we asked screening and background questions to better understand active senior travelers' motivations and expectations: It was important to understand what pushed travelers to visit the destination, how the searching process took place, and what previous expectations the visitors had before using the services provided (customer orientation). The second interview concentrated on the evaluation of technological immersive devices (interactive touch screens and videos): We asked the visitors to provide information about the content, functionality, and utility of the devices that they used. This part gave us an idea about how visitors perceived the 
interface of the device and if the information provided by the device was useful, simple, smooth and easy to be used. Thus, visitors were able to point out some concerns related to the functionality of the device in order for it to be fixed, if needed (Perceived value in use). Moreover, concerning the hedonic dimension, we asked the visitors if their experience met their prior expectations, and we asked them to assess their emotional state for the overall experience when using ICT products (interaction between the user and the product). For example, they were asked if it was fun and pleasurable to use or not, if it had enriched their knowledge, also about the overall level of satisfaction of the visit, and most importantly, if they would repeat the same experience and recommend it to others. It is worth noting that the interviewees were not asked about the economic value of their experience as all of the technological services were offered for free. Additionally, we collected demographic information such as name, gender, age, education, income, occupation, nationality, and level of interaction with technologies.

For this case, the Snowball sampling technique was used to recruit interviewees since patterns could only be identified after the coding of the initial interview with active senior travelers (Biernacki \& Waldorf, 1981).

When new patterns stopped emerging, no more interviews were conducted. In total, the data were collected from 23 interviewees. Table 1 summarizes the main characteristics of the interviewees noting that all the names were invented.

The interviews were conducted while in the field. They were recorded and stored in electronic format on a Dictaphone before being translated, when necessary, and then transcribed.

In addition, direct observations were conducted in three distinct days. These observations were made during the museum opening hours. We observed how active senior travelers were interacting with and using the technologies made available by the museum. Moreover, we took notes during the observations and we used the thick description technique to enrich the content (Geertz, 1973, Yin, 1994).

The analysis of such a largely qualitative data was conducted through the software package Nvivo11 for its capacity to support the storage, cross-referencing and analysis of large amounts of data in multiple different formats such as texts, images, audio files, etc. (Bazeley \& Jackson, 2013). Differentiating the data sources and collecting data from two sources were employed to triangulate the analysis in an attempt to generate robust conclusions (Benbasat, David, \& Melissa, 1987; Eisenhardt 1989; Yin 1994; Dubé \& Paré 2003).

\section{Insert Table 1 about here}

\section{Data Analysis}

Inductive logic was used to analyze the set of data and to arrive at conclusions about the information gathered, thus formulating a theory that is based on the interpretation of the data rather than setting out with a predetermined hypothesis to prove or disprove. In doing so, a within-case analysis was performed (Eisenhardt, 1989; Eisenhardt \& Graebner, 2007). This analysis was done reading the interviews as many times as needed to identify the presence of key elements that led 
to the identification of significant statements. In-depth theoretical categories were examined during the coding procedures (Strauss \& Corbin, 1998). To analyze each interview and the rest of the dataset, a three-step coding process was used. First, the three authors coded the phrases considered as good units of text. When a new potential code was identified, a definition and an example of codes were provided (See Table 2) (Miles \& Huberman, 1994; Boyatzis, 1998). The code structure was implemented and enhanced during the coding process. In the second step, the coding outputs were compared to pinpoint mutual problems and differences, and to develop the first structure of emerging themes and their links. As the coding process continued, the list of codes changed, new codes were introduced and some others were merged. Throughout the data analysis process, the new transcripts were compared with the previously coded data (Strauss \& Corbin, 1998). We stopped conducting interviews (hence the coding process) when we found no more emerging themes from the dataset arriving at the theoretical saturation (Strauss \& Corbin, 1998). At this point, reliability was checked and found satisfactory, and coefficient $\mathrm{K}$ was above 0.8 . Furthermore, the main codes were ordered into two parent nodes (Perceived value and Satisfaction) of similar categories. Perceived value had five dimensions out of which subcategories (child nodes) were drawn. Satisfaction, on the other hand, had three subcategories. The third stage of the coding concerned a process of pattern identification (Miles \& Huberman, 1994). Here, great volumes of data from the two previous steps of coding were condensed into a smaller number of constructs that were considered relevant to understanding the emerging theory. The findings from the abovementioned coding process are displayed in the next paragraph. Table 2 shows the major patterns and their labels, definitions, descriptions, and illustrative examples.

\section{Insert Table 2 about here}

\section{Findings}

In this section, some of the key findings about the technological perceived value of active senior visitors within museum digital transformations are outlined.

\section{Epistemic Value}

All visitors were particularly motivated to visit the archeological museum, to have an overview of Sardinia's history, as well as to deepen their knowledge and satiate their curiosity about the Nuragic civilization. For some, the museum was a good starting point for their trip to check which touristic sites they were interested in visiting during their stay: "We were interested to go there so we can prepare our trip effectively and know better where to go". For others, it was their last stop as they found it a good place to summarize what they have already seen in previous sites and get to see some of the missing historical monuments to complete the picture in their heads: "We already visited the cities of Nora and Tharos, we had much information that were general. Visiting the museum gave us a global understanding of the history of the island, Sardinia. Have a better chronological understanding of several civilizations... " Herve said.

Furthermore we investigated whether seniors have gained their prior knowledge through the website of the museum. In fact, none of the participants used the website to seek general information. They all preferred to gain their knowledge through traditional means like guide books, tour guides and friends. Titziana and Alberto mentioned that they would prefer to access the website after their visit, to refresh their memories about what they have seen and to search deeper 
by reading more about some of the pieces that caught their attention during their visit to the museum.

It is noteworthy that word of mouth and guide books have played an important role in shaping the prior expectation of tourists about their visits. "We have met a lot of friends that have been in here and said it is a fantastic museum and we agree!"

\section{Interest in Use: Challenges and Opportunities Brought to Life}

\section{Some are concerned about the use of technology}

Not knowing how to use the device: Concerns about not knowing how to use the device were expected. For example Carla explained: "We won't use it, because we are old for this technology (laughing)". Also, Marc was only interested to try it if it was "easy to be used". On the other hand, Danielle pointed out that she had never used an immersive mobile application but was interested and willing to try. Catherine noted a new insight related to her acceptance to try new technologies and explained that she would be interested in trying it, as long as it was not something she must put on her head. The expression on her face explicitly divulged her concerns related to hygiene, as she preferred to experience immersive technologies through her phone that she had been actually using it comfortably at the age of 71 , without having to touch a device that has been used by a multitude of tourists.

Missing the real experience: Many have pointed out their lack of interest in using AR not because they did not have enough knowledge or interaction with the digital world, but because they would appreciate seeing the pieces or exhibits as Herve stated "in their classical form". Alberto explained that he preferred to be in the moment rather than to be distracted by the digital layering that could hinder him from seeing and appreciating the real archeological pieces. Sara shared Hervés' and Albertos' opinions about "being there in the moment" stating that she did not feel related to the use of new devices and referred their use to younger generations: "No I didn't use them. I am not so interested in these kinds of things. I am more interested in seeing the art effects. But maybe for children or young students! It's more interesting to have these technological things, but I am not so attracted. "In contrast, she continued by explaining that she would be interested in using mobile applications, only if the device would demonstrate intangible aspects that are hard to exhibit in real life: "I mean... maybe if there was some recreation of how the life was in classical times, like how the people were living in that time. [...] I like to see objects that people were using. So maybe, if there were some recreations of how life was for the people, imagining how their houses were, how their markets were, something like that would be nice!"

Losing human interaction: Milena stated: "I am against this technology, because I found, it's more useful to touch the objects... We would prefer if there was a tour guide, yes! A person that responds to our questions and not general questions registered on a machine."

\section{Others Support the Use of Mobile Application}

On the other hand, as aforementioned, seniors nowadays are more interested in using ICT products in their daily lives and are adopting them faster when such products are perceived beneficial to 
their way of life (Kok et al., 2012; Anabel et al., 2016). We found three main reasons why active senior visitors like these technologies:

Bringing the hidden to display: In fact, Zomar told us: "I am in favor of new technologies, because you have more insight on the things that are on display and it can relate to something that happened thousands of years ago and make it your own".

Getting overview: Gill explaining her way to use new technologies said: "I personally wanted an overview. So, I didn't need to read about every art effect [in the website], I was more interested in learning about the Nuragy and the burial tombs. [...] So, I didn't read everything.".

Listening instead of reading: Hedda our oldest participant (74 years old) was interested in using videos and other immersive technologies because she had visual constraints. She stated: "I would, [use of ICT] well because I can listen to it instead of reading”.

\section{Functional Value}

We found from seniors' answers that they prefer simple, user-friendly devices to navigate, with some labeled explanations in different languages along with panels set aside to characterize the theme of each of the sections in the museum.

Suggestions were given to provide different applications whereby visitors can select their preferred language and better interact with the visual representations of videos with sound effects. "The only enhancement is to have the information in English as well, that would be perfect and I think that if technology was more included, our experience would be better.

I recommend like a touch screen where there are four languages and at the screen that explains about the Nuragy civilization". Milena, in fact, claimed that she needed more engaging videos that would stimulate the mind: "No (with a laughter) they [videos] were beautiful but not interesting. Because they do not stimulate the imagination".

\section{Emotional value}

When visiting museums, visitors expect to experience easiness and fun, cultural entertainment, personal identification, historical reminiscence and escapism (Sheng \& Chen, 2012). Emotional value plays an important role in consumers' behavior and their intention to repeat the use of the device. Zomar explained about her positive past experience with the Louvre mobile application, hence the satisfaction related to her prior experience encouraged her to consider the use of the same type of technologies at a different touristic site: "I went a few times to the Louvre museum. [...] you can download the application of the Louvre and then read and go with your mobile phone and look at whatever you want to see. I would definitely use it in this museum too!"

Mrs. Smith added by stating her excitement when evaluating her level of satisfaction: "I feel it brings me back to those times, [...]. I mean I could visualize these people that these masks belong to. I was excited." 


\section{Social Value}

Many of the interviewed seniors were satisfied with their overall visit to the museum and would recommend it to their friends and families. However, they were unsure to repeat the visit since in their capacity as travelers they would not know exactly when they will revisit the island. As for the locals, they have stated that they would revisit the museum in case new objects were introduced to the exhibition. Finally, on the subject of re-using the same technological devices in another touristic context, those who were pro-use would repeat the experience while those who were against would not: "I have already sent some pictures in groups of WhatsApp and definitely would share my review with the people around me and recommend it" Milena said.

\section{Discussion and theoretical contribution}

We believe this study provides three important insights. First, our findings extended our knowledge on the perceived consumers' value of active senior visitors for the introduction of immersive technologies at archeological museums. Although previous research on perceived value in the tourism field has been extensive (Sánchez-Fernández \& Iniesta-Bonillo, 2007), such literature often lacked the cohesive approach to understanding how the introduction of new means of technological devices and immersive technologies at archeological museums is perceived by senior visitors. Rather, previous work has tended to focus on digital natives (Muskat, at al., 2013). Secondly, our study sheds new light on the different dimensions of the perceived value (epistemic value; functional value; hedonic value and social value) of active senior visitors within museum transformation. A third contribution of our study consists in providing an integrative framework for extending the bounderies of the museum technological visit experience: linking the pre, during and post visit phases. In fact, marketers recognize that consumers' behavior is an ongoing process of exchange that entails the entire consumption course which includes the factors that influence the consumers before, during and after their purchase (Solomon, 2014); also they recognize that understanding the consumers' buying decision process and their perception is an important parameter to create some valuable satisfactory experiences. Since only few studies provide some empirical evidence on the extended space of the technological experience, we have decided to study the case of the National Archaeological Museum of Cagliari because first, it is the most visible one for tourists in terms of preserving the Sardinian "Nuragic" heritage, and second it is more successful than other ventures in the area and has recently introduced digital services aiming at engaging its customers. Our inductive single case study addressed the research question and has yielded five perceived value dimensions (see Table 2).

Finally, our findings suggests the below:

Before the visit - on the personal context: The age, educational level, and technological readiness where not the main reasons for not engaging in technological usage.

During the visit - on the physical context: Museum display of technological services has great importance in attracting the attention of seniors. Nevertheless, seniors still favor human interaction and being there at the moment over the usage of digital devices.

After the visit - on the social context: Seniors demonstrated a very low level of engagement with social media platforms and rarely rated or wrote reviews on the afromentioned museum social media platforms. 


\section{Managerial Implications}

Recognition of the importance of the different dimensions of value should enable museum managers to develop more sophisticated positioning strategies (Sweeney \& Soutar, 2001).

The results of this study show that efficient museums should consider, when introducing new technological devices, distinct criteria including those of the epistemological, social, functional and hedonic values through illustrating an extended space in the pre/during/post phases of visit (See Table 3).

\section{Insert Table 3 about here}

First, we viewed the epistemic value related to technological use, and this enabled us to categorize digital seniors into two groups according to their interests: 1) "Traditional visitors": Seniors who are motivated to use technology but prefer to have a fast-general view over the exhibits at the museum; 2) "Non-traditional visitors": Seniors who are more in depth oriented and demand applications with a richer and more detailed content.

We believe that museum managers should better understand digital seniors' heterogeneity and interest, hence creating tailored applications accessible in different languages that are suitable to different types of visitors. We hereby propose the development of the following applications:

1) General application: for people who would like to have a fast general overview of the museum; 2) Specialists application: for people who would like to deepen their knowledge by focusing in details on their interest while skipping the rest; 3) Experts application: for people who would like to enjoy the benefits of technology as well as the human interaction.

Moreover, visitors will have the option to be accompanied by professional local tour guides, together with the use of devices to support the tour guides explanations, hence enabling them to ask any related questions.

Thus, recognizing the value of traditional and non-traditional senior travelers was imperative in understanding the right implications that would affect the museum when going digital.

Second, during the visit, we used two perceived values dimensions: Hedonic and Functional values. It is recommended that the management would invest in the training of its employees, especially the security guards since they are the people who spend the most time close to the art pieces and have direct contact with tourists. It would certainly be an added value to visitors to obtain additional information and assistance from any of their encountered employees at the museum. Moreover, the management should market the museum by highlighting one or two artifacts as main attraction points, rendering the museum frequently mentioned in articles, magazines and online websites, hence encouraging traditional visitors to take action and choose this location as a "must-see museum".

In terms of targeting traditional visitors, it is recommended to organize events that would actively engage these visitors, such as involving them in watching an artist in action. In order to ensure a high level of functional values, the application should comprise some entertaining videos highlighting general overview information while discarding the less important details; this will keep the interactive experience simple, but vibrant and entertaining. It is also recommended that 
the application would be provided in multiple languages. As for the non-traditional visitors, the application should highlight the details while giving the option to skip, shift or choose the topic of interest.

After the visit, it is advisable to create a professional photo booth with the same museum ambiance along with figurines representing the highlighted pieces of art thus enticing traditional visitors to $\log$ into their social media account and follow the museum social page in order to retrieve their pictures. Hence they will not only share their personal details with the museum but also will indirectly market the location among their social media friends. As for the non-traditional visitors, offering them the opportunity to share their experience on the museum's blog by writing articles and sharing their art or creation would attract other non-traditional visitors.

\section{Study Limitations and Future Research}

The present study presents some limitations. First, it was conducted in the archeological museum of Cagliari, south of Italy; hence the strategic approach that was unveiled cannot be generalized to other types of museums elsewhere. Second, we opted a qualitative research strategy; however, the next step would be to use a quantitative approach to better generalize our findings. Third, this study focused on the perceived value of active senior travelers using the technology within an indoor environment. It would be interesting to explore if the perception of seniors would change when such technology is used in outdoor environments. Fourth, as mentioned in the methodological section, since the devices used at this museum were offered for free, our study excluded the economic value from the perceived value dimensions. Thus, another interesting theme for future research would be to evaluate the economic dimension implication on the overall experience at the museum.

Finally, Wilkening and Chung (2009) emphasized that museum visitors, as they do at different stages of their lives, will have different needs and perceptions. Conducting a longitudinal study evaluating the same population of seniors over a longer period would enhance our understanding of perception and adoption behavior of non-users.

\section{References}

Atembe, R. (2015). The use of Smart Technology in tourism: evidence from wearable devices. Journal of tourism and hospitality management, 3(11-12), 224-234.

Anabel Quan-Haase, Kim M., \& Kathleen S. (2016). Interviews with digital seniors: ICT use in the context of everyday life. Information, Communication \& Society, 19(5), 691-707.

Baxter, P. \& Jack, S., 2008. Qualitative case study methodology: Study design and implementation for novice researchers. The qualitative report, 13(4), pp.544-559.

Bazeley, P., \& Jackson, K. (2013). Qualitative data analysis with NVivo. London: Sage Publications Limited.

Benbasat, I., David K. G., \& Melissa M. (1987). The case research strategy in studies of information systems. MIS Quarterly 369-386.

Biernacki, P., \&Waldorf, D. (1981). Snowball sampling: Problems and techniques of chain referral sampling. Sociological Methods \& Research, 10(2), 141.

Boyatzis, R.E. (1998). Transforming qualitative information: Thematic analysis and code development. London: Sage publishing. 
Buhalis, D. (2003). eTourism: Information Technology for Strategic Tourism Management. London: Pearson education.

Cabiddu, F., De Carlo, M., \& Piccoli, G. (2014). Social media affordances: Enabling customer engagement. Annals of Tourism Research, 48, 175-192.

Caro, M.S., Soto, M.D.C.S., Ramírez, M.R., Rojas, E.M., Moreno, H.B.R. \& Zúñiga, L.G.L., (2016). Mental Activation of Seniors Incorporating ICT in Their Daily Lives. In Innovation in Medicine and Healthcare 2015 (pp. 85-92). Springer, Cham.

Chung, N., Han, H. \& Joun, Y. (2015). Tourists' intention to visit a destination: The role of augmented reality (AR) application for a heritage site. Computer in human behavior, 50, 588-599.

Chung, Namho, Hyunae Lee, Jin-Young Kim, and Chulmo Koo. "The Role of Augmented Reality for Experience-Influenced Environments: The Case of Cultural Heritage Tourism in Korea." Journal of Travel Research (2017): 0047287517708255.

Cotten, Shelia R., William A. Anderson, and Brandi M. McCullough. "Impact of internet use on loneliness and contact with others among older adults: cross-sectional analysis." Journal of medical Internet research 15.2 (2013).

De Rojas, C. \& Camarero, C., 2008. Visitors' experience, mood and satisfaction in a heritage context: Evidence from an interpretation center. Tourism management, 29(3), pp.525-537.

Dieck, M. C., \& Jung, T. H. (2017). Value of augmented reality at cultural heritage sites: A stakeholder approach. Journal of Destination Marketing \& Management, 1-8.

Dubé, L., \& Paré, G. (2003). Rigor in information systems positivist case research: current practices, trends, and recommendations. MIS Quarterly, 597-636.

Economou, M. \& Meintani, E., 2011. Promising beginning? Evaluating museum mobile phone apps.

Eisenhardt, K. M. (1989). Building theories from case study research. Academy of Management Review, 14(4), 532-550.

Eisenhardt, K. M., \& Graebner, M. E. (2007). Theory building from cases: Opportunities and challenges. Academy of Management Journal, 50(1), 25-32.

Eriksson, N., \& Fabricius, S. (2015). Young-Elderly Travelers as potential users and actual users of Internet with mobile devices during Trips. Open and big data management and innovation. Series notes in computer science, (9373), 24-35.

Eurostat, tourism trends and ageing (2016). Accessible online at: http://ec.europa.eu/eurostat/statistics-explained/index.php/Tourism_trends_and_ageing

Falk, J.H. and Dierking, L.D., 2000. Learning from museums: Visitor experiences and the making of meaning. Altamira Press.

Kraemer, H. \& Kanter, N., 2014, December. Use and re-use of data how Collection Management Systems, Transmedia and Augmented Reality impact the future of museum. In Virtual Systems \& Multimedia (VSMM), 2014 International Conference on (pp. 214-216). IEEE.

Geertz, C. (1973). The interpretation of cultures: Selected essays (Vol. 5019). Basic books.

Grant, R.M. (1991). The resource-based theory of competitive advantage: implications for strategy formulation. California management review, 33(3), 114-135.

Gregory, G., Dess, G. T., Lumpkin, A. and Einer, B. (2010). Strategic Management creating competitive advantages, fifth edition, pp. 25-31.

Gretzel, U. (2011). Intelligent systems in tourism: A social science perspective. Annals of tourism research, 32(3), 757-779. 
Gustafson, D; McTavish, F.; Gustafson Jr.; Mahoney, J; Johnson, R; Lee, J. Quanbeck, A; Atwood, A; Isham, A., Veeramari, R.; Clemson, L \& Shah, D. (2015). The effect of an information and communication technology (ICT) on older adults' quality of life study protocol for a randomized control trial. Trials study protocol. 16:191 DOI 10.1186/s13063-015-07132.

Haight, M., Quan-Haase, A., \& Corbett, B. (2014). Revisiting the digital divide in Canada: The impact of demographic factors on access to the internet, level of online activity, and social networking site usage. Information, Communication \& Society, 17(4), 503-519.

Hogsden, C., \& Poulter, E. K. (2012). The real other? Museum objects in digital contact networks. Journal of material culture, 17(3) 265-286.

Holbrook, M.B. (2006). Consumption experience, customer value, and subjective personal introspection: An illustrative photographic essay. Journal of business research, 59(6), 714-725.

Hooper-Greenhill, E., 2006. Studying visitors. A companion to museum studies, pp.362-376.

Huang, L. \& Tsai, H.T. (2003). The study of senior traveler behavior in Taiwan. Tourism management, 24, 561-574.

ICOM, Museum definition. 22 ${ }^{\text {nd }}$ General Assembly. Vienna, Austria, August $24^{\text {th }}, 2007$.

Im, D. J., Ku, J., Kim, Y. J., Cho, S., Cho, Y. K., \& Lim, T., (2015). Utility of a three dimensional interactive augmented reality program for balance and mobility rehabilitation in the elderly: A feasibility study. Annals of Rehabilitation Medicine, 39, 462-472.

Ippolito, J., \& Bell, J., 2015. Diffused Museums: Networked, Augmented, and Self-Organized Collections. The International Handbooks of Museum Studies.

Jang, S. S., Bai, B., Hu, C., \&Wu, C. M. E. (2009). Affect travel motivation, and travel intention: A senior market. Journal of Hospitality \& Tourism Research, 33(1), 51-73.

Jang, S.S. \& Ham, S., 2009. A double-hurdle analysis of travel expenditure: Baby boomer seniors versus older seniors. Tourism Management, 30(3), pp.372-380.

Jang, S. S., \& Wu, C. M. E. (2006). Seniors' travel motivation and the influential factors: An examination of Taiwanese seniors. Tourism Management, 27(2), 306-316.

Johnson, L., Adams Becker, S., Estrada, V. \& Freeman, A. (2015). The NMC Horizon Report: 2015 Museum Edition. New Media Consortium. 6101 West Courtyard Drive Building One Suite 100, Austin, TX 78730.

Kok, A., Williams, K., \& Yan, H. (2012). Seniors skyping: A professional, academic, and community collaboration. The Journal of Community Informatics, 8(1), 1-12.

Kaplan, A. M., \& Haenlein, M. (2010). Users of the world, unite! The challenges and opportunities of Social Media. Business Horizons, 53, 59-68.

Kazeminia, A., Del Chiappa, G., \& Jafari, J. (2015). Seniors' travel constraints and their coping strategies. Journal of travel research, 54 (1), 80-93.

Kim, M. J., Lee, C., \& Bonn, M. (2016). The effect of social capital and altruism on seniors' revisit intention to social network sites for tourism-related purposes. Tourism management, 53, 96-107.

Kourouthanassis, P., Boletsis, C., Bardaki, C. \& Chasanidou, D., 2015. Tourists' responses to mobile augmented reality travel guides: The role of emotions on adoption behavior. Pervasive and Mobile Computing, 18, pp.71-87.

Larsen, S., 2007. Aspects of a psychology of the tourist experience. Scandinavian Journal of Hospitality and Tourism, 7(1), pp.7-18. 
Liang, T. P., \& Turban, E. (2011). Introduction to the special issue social commerce: a research framework for social commerce. International Journal of electronic commerce, 16(2), 514.

Matt, C., Hess, T., \& Benlian, A. (2015). Digital Transformation Strategies. Business and Information Systems Engineering, 57(5), 339-343,

McCabe, S. (2014). The Routledge handbook of tourism marketing. Routledge.

McMurtrey M. E., Steven M. Z., James P. D., \& Ronald E. M. (2011). Seniors and Technology: Results from a Field Study. Journal of Computer. Information Systems, 51(4), 22-30.

Merriam, S.B., 1998. Qualitative Research and Case Study Applications in Education. Revised and Expanded from" Case Study Research in Education.". Jossey-Bass Publishers, 350 Sansome St, San Francisco, CA 94104.

Miles, M. B., \& Huberman, A. M. (1994). Qualitative data analysis (2nd ed.). Thousand Oaks, CA: Sage publishing.

Muskat, M., Muskat, B., Zehrer, A., \& Johns, R. (2013). Generation Y: evaluating services experiences through mobile ethnography. The Tourist Review, 68 (3), 55-71.

Morisson, Alex (2017). Digital Strategy for Museums. A practical guide for museums (and other organisations) that want to do more with their digital programmes) February. Gogapp.

OP\&A. (2007). 2030 Vision: Anticipating the needs and expectations of museum visitors of the future. Washington: Smithsonian Institution, Office of Policy \& Analysis.https://www.si.edu/Content/opanda/docs/Rpts2007/07.07.2030Vision.Final.pd f Retrieved 25/6/2017

Parasuraman, A., (1997). Reflections on gaining competitive advantage through customer value. Journal of the Academy of marketing Science, 25(2), 154.

Patuelli, R., \& Nijkamp, P. (2016). Travel motivations of seniors. A review and a meta-analytical assessment. Tourism economics, 22(4), 847-862.

Pesonen, J., Komppula, R., \& Riihinen, A. (2015). Typology of senior travelers as users of tourism information technology. Information Technology \& Tourism, 15(3), 233-252.

Pettigrew, A. M. (1990). Longitudinal field research on change: Theory and practice. Organization Science, 1(3), 267-292.

Presbensen, N. K., Vitterso, J., \& Dahl, T. (2013). Value co-creation significance of tourist resources. Annals of tourism Research, 42,240-261.

Sánchez-Fernández, R. \& Iniesta-Bonillo, M.Á. (2007). The concept of perceived value: a systematic review of the research. Marketing theory, 7(4),427-451.

Sandberg, J., \& Tsoukas, H. (2011). Grasping the logic of practice: Theorizing through practical rationality. Academy of Management Review, 36(2), 338-360.

Saracchini, R., Catalina-Ortega, C., \& Bordoni, L. (2015). A mobile Augmented Reality Assistive technology for the elderly. Comunicar Journal, 23(45), 65-7.

Schröder, Achim, and Torsten Widmann. "Demographic change and its impact on the travel industry: Oldies-nothing but goldies?" Trends and issues in global tourism 2007. Springer Berlin Heidelberg, 2007. 3-17.

Sfandla, C. and Björk, P., 2013. Tourism Experience Network: Co-creation of Experiences in Interactive Processes. International Journal of Tourism Research, 15(5), pp.495-506.

Sheng, C.W. \& Chen, M.C. (2012). A study of experience expectations of museum visitors. Tourism management, 33(1), 53-60.

Sheth, J.N., Newman, B.I. \& Gross, B.L. (1991). Why we buy what we buy: A theory of consumption values. Journal of business research, 22(2), 159-170. 
Solomon, M. R. (2014). Consumer behavior: Buying, having, and being (Vol. 10). Upper Saddle River, NJ: Prentice Hall.

Stephen, A. T., \& Toubia, O. (2010). Deriving value from social commerce networks. Journal of marketing research, 47(2), 215-228.

Stickdorn, M. \& Schwarzenberger, K. (2016). Service design in tourism. Entrepreneurship und Tourismus: Unternehmerisches Denken und Erfolgskonzepte aus der Praxis, 261.

Stogner, M. B. (2013). Searching for Aristotle in the Digital Age: Creating Cultural Narrative with $21^{\text {st }}$ century media technologies. The International Journal of New Media, Technology, and the Arts, 8.

Strauss, A., \& Corbin, J. (1998). Basics of qualitative research: Techniques and procedures for developing grounded theory. Thousand Oaks, CA: Sage Publications.

Siu, N.Y.M., Zhang, T.J.F., Dong, P. and Kwan, H.Y., 2013. New service bonds and customer value in customer relationship management: The case of museum visitors. Tourism Management, 36, pp.293-303.

Sweeney, J.C. \& Soutar, G.N. (2001). Consumer perceived value: The development of a multiple item scale. Journal of retailing, 77(2), 203-220.

Tsoukas, H. (2010). Practice, strategy making and intentionality: a Heideggerian onto- for strategy as practice. Cambridge Handbook of Strategy as Practice, 47-62.

Wang, E.H.H. and Chen, C.Y., 2011, January. System quality, user satisfaction, and perceived net benefits of mobile broadband services. In Proceedings of 8th International Telecommunication Society Asia-Pacific Regional Conference Taiwan (pp. 26-29).

Wang, Y., Lo, H.P., Chi, R. \& Yang, Y. (2004). An Integrated Framework for Customer Value and Customer-Relationship-Management Performance: A Customer-Based Perspective from China. Managing Service Quality, 14(2-3), 169-82.

Weil, S. (2007). "From Being about Something to Being for somebody: The ongoing transformation of the American museum", in Sandell, R. and Janes, R.R. eds., 2007. Museum management and marketing. Routledge.

Welsh, J., Alijani, G., \& Smith, K. (2009). Proceeding of the Academy of information and management science, 13 (1), 82.

WHO, World health organization (September 2015). Ageing and health report. Accessible online at: http://www.who.int/mediacentre/factsheets/fs404/en/

Wilkening, S., \& Chung, J. (2009). Life stages of the museum visitor: Building engagement over lifetime. Washington, DC: American Association of Museums.

Xu, F., Weber, J., \& Buhalis, D., 2013. Gamification in tourism. In Information and Communication Technologies in Tourism 2014 (pp. 525-537). Springer, Cham.

Yin, R. (1994). Case study research: Design and methods . Beverly Hills. CA: Sage publishing.

Zeithaml, V.A., 1988. Consumer perceptions of price, quality, and value: a means-end model and synthesis of evidence. The Journal of marketing, pp.2-22. 